\title{
O ADEUS ÀS VIOLAS: A MANUTENÇÃO DA TRADIÇÃO DA FOLIA DE REIS ENTRE OS PATRIMÔNIOS RURAIS E OS BAIRROS DE LONDRINA (PR) A PARTIR DA TRAJETÓRIA DE VIDA DO EMBAIXADOR FRANCISCO GARBOSI
}

\author{
André Camargo Lopes
}

\section{RESUMO}

A Folia de Reis é uma festa popular religiosa uma forma de expressão em que seus agentes congregam em si perspectivas subjetivas de interpretação e prática ritualística acerca de seu próprio universo religioso. O presente trabalho é resultado de uma série de entrevistas realizadas com o senhor Francisco Garbosi, embaixador da Companhia de Reis Mensageiros da Paz, residente no Conjunto Habitacional Semíramis Braga, na zona norte do município de Londrina-PR. Procura-se através destas entrevistas realizadas entre os anos de 2005 e 2008 colocar em evidência temas como: a formação das Folias de Reis locais e o papel do núcleo familiar nas estratégias de transmissão e manutenção da tradição. Assim como, pretende-se problematizar a luz dos núcleos formadores a relação da tradição de Santos Reis na área urbana, a organização e a lacuna etária quando da pesquisa, com as atuais entrevistas concedidas pelo embaixador aos veículos de comunicação locais entre os anos de 2010 e 2016.

Palavras chaves: tradição, Folia de Reis, Embaixador, patrimônio

A tradição de Folia de Reis reflete uma dimensão do catolicismo popular brasileiro, a qual se caracteriza pelo dinamismo interpretativo e a presença e a centralidade na figura do mestre ritual. As reflexões resultantes na redação deste trabalho tiveram como referencial um conjunto de depoimentos coletados entre os anos de 2005 e $2008^{1}$ com o Embaixador de Reis Francisco Garbosi. Essas entrevistas revelaram um sentimento paradoxal diante da tradição que segundo ele adentrou ao município pelo Patrimônio Rural de Irerê, por meio de famílias de migrantes mineiros, dentre as muitas a sua, renovada de geração a geração. Uma tradição devocional rememorada a cada verso, no cantar, no ritual, contribuindo para a construção e preservação de uma identidade familiar, pautada em raízes regionais. Porém, essas entrevistas revelaram a fala do velho Embaixador de Reis a preocupação com a falta de renovação em seu grupo, quase com a certeza do fim de sua identidade familiar e cultural na região. Este artigo se propõe revisitar o problema central apreciado nas entrevistas (a renovação etária e a adaptabilidade da tradição ao espaço urbano) e compreender as atuais condições das Companhias de Reis na região norte do município de Londrina (PR) em 2016. Para isso confrontaremos as entrevistas e as observações de campo realizadas entre 2005-2008 e as entrevistas concedidas aos veículos de comunicação do embaixador Francisco Garbosi, líder da Companhia de Reis Mensageiros da Paz (uma das principais vozes na luta pela preservação da tradição de Reis) confrontando-a com a organização atual de sua Companhia e as estratégias adotadas por esse embaixador na tentativa de preservação da tradição de Reis.

\footnotetext{
${ }^{1}$ Esse levantamento foi realizado durante meu Mestrado em História Social, em que entrevistei os embaixadores Francisco Garbosi, Antonio Francisco Lopes e Joaquim André, responsáveis pelas três Companhias de Reis existentes na região norte dom município de Londrina.
} 


\section{SEMINÁRIO DE PESQUISA EM CIÊNCIAS HUMANAS - SEPECH \\ Humanidades, Estado e desafios didático-científicos \\ Londrina, 27 a 29 de julho de 2016}

\section{Embaixadores: a educação dos mestres no catolicismo popular}

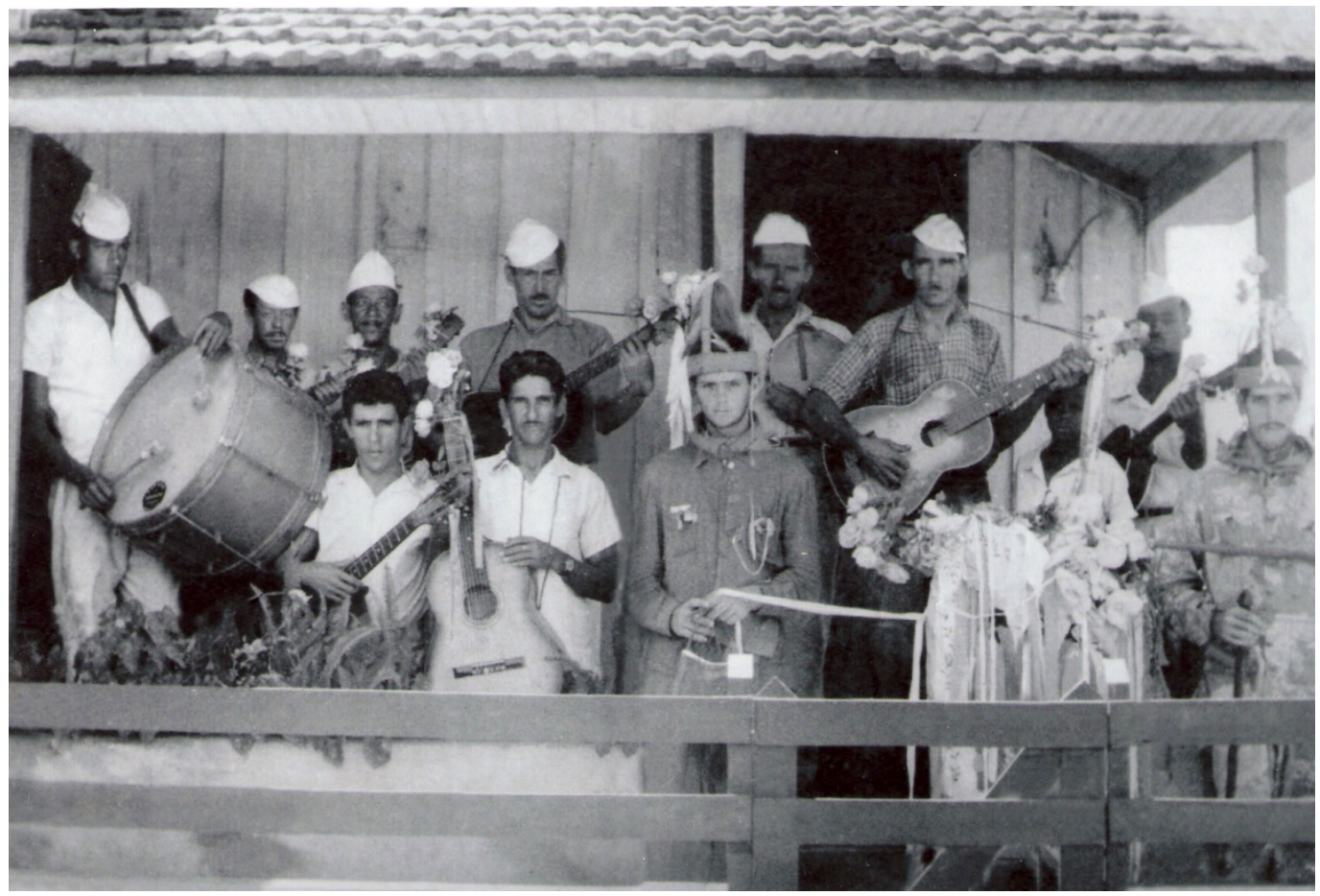

Guaravera 1961 - Grupo de Reis dos Flausino. Na caixa está Adelson, abaixo da caixa encontra-se Francisco Garbosi e Sebastião Flausino, em seguida o Bastião Aquiles, com Lazaro Flausino à porta, em pé, e o segundo Bastião, Benedito Garboza (os outros integrantes não foram identificados pelo senhor Francisco Garbosi).

Fonte: Acervo familiar de Francisco Garbosi.

A formação dos mestres rituais no catolicismo popular brasileiro, tem como principal característica a sua constituição doméstica. Um dos filhos herda o posto do pai (ou da mãe, do tio etc.), através de um lento processo de educação, em que a formação religiosa se fundamenta na base estrutural da visualização de mundo destes agentes, isso é reafirmado por Francisco Garbosi ao se remeter a sua origem como folião e posteriormente embaixador:

Meu pai logo que eu comecei a me entender por gente ele já era folião de Reis. Então quando ele trazia aquelas Companhias de Reis. Minha casa tinha presépio.

Aqueles cara vinha tocando. $\mathrm{O}$ bandolim principalmente, aquela cordinha tremidinha assim, parece que eu tremia meu coração quando eu era pequeno, e continua até hoje. Então, eu não sei explicar direito, é uma coisa que vem de dentro, tipo do âmago da pessoa... E o Santos Reis é uma coisa mística. Uma coisa que talvez é... Aquela mistificação do desconhecido.

Sei lá deve ser isto né? Aquela busca pelo mistério dos Reis Magos. O mistério do nascimento de Jesus que envolve tudo aquilo né? Aquela coisa, aquela busca pelo mistério, que me fez, eu tenho uma fé muito grande nos Reis magos. 


\section{SEMINÁRIO DE PESQUISA EM CIÊNCIAS HUMANAS - SEPECH \\ Humanidades, Estado e desafios didático-científicos \\ Londrina, 27 a 29 de julho de 2016}

E veio como eu tô falando, tocava a viola... O bandolim, que eles chamavam de violão quando eu era pequeno. Tocava aquela violinha, e conforme eles tremia a corda meu coração parecia que tremia junto. E eu pensava que um dia eu ia ser cantadô de Reis, e graças a Deus consegui.

Em sua fala reforça o princípio da formação doméstica dos mestres da religiosidade popular. Uma formação em que devoção e tradição se misturam, o embaixador Francisco Garbosi não foge à regra: mineiro de Paraguaçu - identidade que exibe como afirmação de seu conhecimento no rito de Folia de reis -, vem de uma família de foliões, em que a tradição de Reis se mistura com a própria história da família ${ }^{2}$. Esta formação dos agentes religiosos é pertinente às discussões de Brandão (1985) acerca do acesso, da formação e dos lugares destes na composição das manifestações coletivas da religiosidade popular. De acordo com o autor, não há lugares sociais separados para o período de iniciação, os agentes se relacionam com o ofício religioso nas suas práticas cotidianas, às quais todos têm acesso, ou seja, o período de aprendizagem é vivido ao longo das práticas religiosas, no qual estes agentes ora participam como observadores, ora como atuantes.

Nesta perspectiva da formação de um mestre ritual de Folia de Reis, Francisco Garbosi, foi ocupar o posto de embaixador no ano de 1970, já no município de Londrina, em uma Companhia de Reis cuja bandeira era de um mestre embaixador do Jardim Marabá ${ }^{3}$.

\section{O PATRIMÔNIO RURAL: REMINISCÊNCIAS DE UM ESPAÇO CULTURAL NAS FALAS DE FRANCISCO GARBOSI}

O catolicismo popular em sua dinâmica, está presente em um universo de práticas absorvidas pela religiosidade popular, e consequentemente a análise de quaisquer que sejam de suas manifestações, os aspectos sociais e culturais reinantes no cotidiano, não podem ser deslocados da análise deste (ZALUAR: 193). São práticas religiosas orgânicas e de senso prático. Os problemas religiosos são pontuais e terrenos, assim como as práticas devocionais. Todavia, como elemento da dimensão social e histórica dos indivíduos essas práticas religiosas sofrem transformações e ressignificações.

Zaluar (1983) ao observar a transição de um modelo de sociedade rural para uma crescente urbanização no Brasil, constatou que tal fenômeno social gerou um forte impacto no ritmo de vida e consequentemente reorientando em muitos aspectos o universo simbólico do migrante do campo. Isso, dentro do universo religioso popular, refletiu na prática, uma significa e gradual transformação nos hábitos devocionais neste

\footnotetext{
${ }^{2}$ Tal como afirma o embaixador "(...) uma tradição familiar"; reafirmada por seus irmãos também integrantes da Companhia de Reis Mensageiros da Paz ("sou folião desde criança, pois os meus pais e os meus tios eram foliões. Com oito (8) anos eu já cantava na Folia." - Sebastião Garbossi Sobrinho, 56 anos). Em sua formação nas Companhias de Reis da região, já menino saia com seu pai em sua Companhia de Reis, pelo patrimônio de Paiquerê, executando a função de "escrivão".

${ }^{3}$ Em função de suas ocupações seculares, este afirma ter saído em jornada apenas um ano, durante o tempo em que trabalhou nas empresas de transporte coletivo da cidade, pois os períodos de férias e folgas não coincidam com o período da jornada da bandeira.
} 


\section{SEMINÁRIO DE PESQUISA EM CIÊNCIAS HUMANAS - SEPECH \\ Humanidades, Estado e desafios didático-científicos \\ Londrina, 27 a 29 de julho de 2016}

trânsito social das comunidades rurais para os centros urbanos ${ }^{4}$. A autora afirma que no contexto urbano, mudou-se o discurso sobre a organização do pagamento da promessa, ao invés de festas e peditórios, centrou-se no uso do ex-votos e nas romarias para cidades-santuários como forma de pagamento.

A dicotomia entre o universo religioso urbano e o universo religioso rural fundamenta a princípio a lacuna etária que se estabelece dentro do grupo. De origem rural, as Companhias de Reis da região, especificamente a Companhia de Reis da família Garbosi, surgem de um núcleo social reduzido em colônias que tem nas festas do calendário religioso o seu momento de lazer devocional e profano.

Nas narrativas de Francisco Garbosi a tradição de Reis na região está diretamente relacionada à vivência de sua família nos patrimônios rurais de Londrina $(\mathrm{PR})^{5}$.Acerca deste cotidiano social, Francisco Garbosi, ao definir o espaço de sociabilidade destes patrimônios, remetem a uma redução das práticas religiosas e sociais, ao grupo rural de vizinhança, o que, nos possibilita afirmar, que são estes pequenos núcleos rurais, agrupamentos mais ou menos densos de vizinhança, cujos limites se definem nos festejos religiosos locais. Em suas lembranças, é o adro da capela e as colônias das fazendas os espaços de manifestações destas atividades de envolvimento popular com o santo de devoção. É no trabalho dos agentes centrados em sua fé, que o embaixador Francisco Garbosi narra as grandes festas ocorridas no patrimônio de Irerê.

Nosso lazer? Naquele tempo se usava chamar de brincadeira. Era uma espécie de baile, baile rural. Então quando alguém falava "vai tê uma brincadeira na casa de fulano. Então você já sabia que era convidado pra dançá".

Então era assim.

E como nóis morava perto também [Irerê]... Morava um quilômetro e meio mais ou menos. Meu pai gritava leilão no coreto da Igreja. Tinha Companhia lá e marcava Quadrilha, Festa Junina.

Então... A vida dele [o pai] tava envolvida com atividades de... De alegria. Danças, jogos, Folia de Reis. O que pintasse... Congo. O que pintasse ele tava no meio. Em matéria de comunicação, ele era comunicativo.(...) É, da capela do Irerê. Ali girava. Ali tinha... Nas fazenda também, a gente fazia os baile, as brincadeiras. Uma espécie

\footnotetext{
${ }^{4}$ Segunda a autora, a mudança de um espaço social para outro mais complexo, gerou transformações nas práticas tradicionais. Em suas observações, o principal agente transformador foi a centralização do simbólico na hierarquização institucional, as irmandades de leigos foram absorvidas e controladas pela hierarquia da Igreja Católica, com isso, os símbolos e os rituais foram adequados a um universo ordeiro e centralizador.

${ }^{5}$ De acordo com as diretrizes gerais do projeto, a colonização deveria viabilizar relações estreitas entre campo e cidades, permitindo facilidade de escoamento e comercialização da produção agrícola, e uma estrutura adequada de atendimento à população migrante que chegava à região. Nestas diretrizes, os patrimônios, enquanto pequenos núcleos populacionais intermediários entre o meio rural e o meio urbano, deveriam garantir a comunicação dos agricultores com as cidades, ao mesmo tempo em que tinham como função, o abastecimento das propriedades situadas em seus arredores e a comercialização dos produtos agrícolas. Desta forma, os patrimônios, ao mesmo tempo em que funcionavam como pequenos centros comerciais e abastecedores intermediários eram espaços onde se desenvolviam as atividades lúdico-religiosas da população rural que residia em suas imediações, assumindo, como aponta Almeida, o papel relevante na estruturação de relações e socioculturais entre os migrantes que se instalavam na região .
} 


\section{SEMINÁRIO DE PESQUISA EM CIÊNCIAS HUMANAS - SEPECH \\ Humanidades, Estado e desafios didático-científicos \\ Londrina, 27 a 29 de julho de 2016}

de baile. (...) Dentro das colônia. Num dia na casa de um colono noutro dia na casa de outro.

Lazer e fé ocupavam o mesmo espaço no que tange as interações sociais. É neste espaço das festas, que encontramos a suspensão da rotina do trabalho e a afirmação do grupo de vizinhança e o reconhecimento do papel social destes agentes no seu núcleo social, seja em um posicionamento claro no trabalho, seja sua importância na festividade produzida pelo grupo.

Em suas reminiscências Francisco Garbosi, expõe a lógica social que envolvia o lazer e fé nestes espaços, reconstruindo a partir de suas experiências pessoais as relações cotidianas destes núcleos sociais.

A organização das festas, as quais, afirma o embaixador, a maioria, eram de origem religiosa, estava sempre em mãos dos próprios colonos. Esta situação organizacional reflete duas situações comuns nas áreas rurais brasileiras neste período: a escassez de sacerdotes nestas regiões, e a manutenção e preservação do catolicismo popular nestes grupos de colonos. O homem que se embriaga é o mesmo que canta e ora. É nesta interpenetração dos espaços que as festas de santos ganham corpo na rotina religiosa. Ao projetar a relação das Companhias de Reis com a Igreja, Francisco Garbosi estabelece as fronteiras entre a Folia de Reis praticada em tempos passados, e a sua leitura ético-religiosa da tradição, incorporando ao rito um elemento distanciador entre estes momentos históricos: o contato dos agentes com a Doutrina Católica.

O universo cultural vivenciado pelo embaixador transita entre um "isolamento" comunitário nas fazendas de café que tendiam a traduzir um catolicismo a partir da lógica de sociabilidade dos próprios agentes. A um catolicismo de comunidades religiosas no espaço urbano, com suas identidades fixas nas representações do campo religioso na qual está inserido - tendo em vista que a mobilidade deste agente dentro do espaço social e, dos papéis assumidos por este em seu bairro em sua comunidade religiosa nos dias atuais.

A complexidade desta rede de relações que concentra o momento religioso como um mediador da suspensão do tempo do trabalho, concentrando das aspirações de lazer do colono, gira entorno do contrato com o santo (promessa). Este formato da organização da celebração do santo coloca a festa do santo como um contrato que antes de tudo é um contrato entre homens acerca de um espaço centrando nos participantes a responsabilidade de preservar, na festa a sua convergência sociabilizadora.

É nesta autonomia estrutural da celebração da festa que repousa os traços de maior riqueza das Companhias de Reis no espaço urbano de Londrina, assim como, o seu campo de maior adequação e conflito.

\section{PREFÁCIO DE UMA TRADIÇÃO: A FOLIA DE REIS OS GARBOSI}

Olha no Estado de São Paulo já tinha contato. Que meu pai era folião então a gente já tinha contato com folia de Reis né?

Ele já saia no Estado de São Paulo.

Aqui no Paraná, foi quando nóis viemo para Londrina, acho eu em cinquenta e quatro... Cinquenta e quatro no Paiquerê. Aí, meu irmão organizou um grupo de folia de reis lá, pra cumpri a promessa do sogro dele que era irmão de meu pai né? 


\section{SEMINÁRIO DE PESQUISA EM CIÊNCIAS HUMANAS - SEPECH \\ Humanidades, Estado e desafios didático-científicos \\ Londrina, 27 a 29 de julho de 2016}

Ai saiu a Companhia do meu irmão, que formou um grupo em nome do meu pai e do meu tio. Daí ele tomou a iniciativa. E esse grupo sai lá no Paiquerê até hoje.

O conhecimento religioso de Francisco Garbosi é moldado em um sistema simbólico ainda sertanejo - que reflete uma visão de mundo muito própria acerca das ideologias religiosas, estabelecendo os seus códigos familiares e sociais, que incorpora elementos fragmentados da História Sagrada, da doutrina e das regras das práticas devocionais da Igreja Católica ${ }^{6}$. A transmissão deste tipo de conhecimento, além da participação direta no rito e na organização da Companhia, tem nas histórias narradas por pais, avós, tios ou vizinhos o seu principal canal de disseminação entre os grupos de jovens destas colônias.

A formação de Francisco Garbosi na tradição da Folia de Reis se confunde com o universo da educação familiar. Evidencia-se em sua narrativa a centralidade no espaço familiar, como a via de acesso e formação à tradição de Folia de Reis, que constitui não só um aspecto da vida religiosa de sua família, mas, sim, um espaço de abrangência e sociabilidade.

Sobre a origem da tradição no núcleo familiar dos Garbosi, foi o seu irmão mais velho que tomou frente do compromisso assumido por seu sogro (e também tio, irmão de seu pai). Esta postura, segundo Zaluar (1980), era prática comum no universo cultural do lavrador brasileiro, “(...) Quando precisava cumprir uma promessa, um indivíduo chamava seus familiares, seus parentes ou seus vizinhos para rezar ou dançar com ele, ou praticava das danças e das festas organizadas na localidade em que vivia" (ZALUAR: 1980, p. 176). Trata-se, portanto, neste tipo de relacionamento, o estabelecimento de uma rede de reciprocidade que transcende as relações familiares com o santo. A estrutura do peditório envolvia, como afirma Francisco Garbosi, todo o núcleo social da colônia, assim como, as colônias vizinhas, ou seja, a promessa era compartilhada por todo o círculo social que tinha na festa a reiteração destes laços.

As festas de arremate era... Era maravilhoso. Tudo o que se ganhava durante a jornada ou o giro da bandeira era empregado na festa. Dinheiro não saia muito, mas alimento saia. Saia leitoa, porco, até boi e alguns... Mé. Tudo era empregado na festa.

E ai, quem deu participa e quem não deu também participa por que a festa de Santo Reis é uma festa popular pra todo mundo né?

É claro que se você deu uma boa oferta. Ele vai te chamar, vai falar "A. vem pra cá"; primeiramente... Primeiro por que tem uma mesa pros folião... Uma mesa dos foliões. E é claro que quem deu almoço pros foliões e é considerado também folião... Eu passei na tua casa e você deu almoço pra Companhia, na hora da mesa dos foliões eu falo "Oh A. faz favor, traz a tua família ai, senta aqui. Senta junto aqui com nós";

\footnotetext{
${ }^{6}$ Em seus estudos acerca da formação dos mestres rituais no catolicismo popular, Brandão (1985) aponta que entre os "sacerdotes populares católicos" são respeitados os direitos de descendência, principalmente os dos mestres e chefes de grupos rituais, como das Companhias de Reis. Nelas os filhos e netos, via de regra, aprendem com pais e avós, a quem servem de auxiliares durante estágios de iniciação; "(...) convocam os seus filhos homens, desde crianças, para ocuparem cargos de trabalho ritual em seus grupos e colocam sobre eles a esperança de continuidade do 'terno', 'companhia' ou 'turma' depois de sua velhice ou morte" (BRANDÃO, 1985: p. 155).
} 


\section{SEMINÁRIO DE PESQUISA EM CIÊNCIAS HUMANAS - SEPECH \\ Humanidades, Estado e desafios didático-científicos \\ Londrina, 27 a 29 de julho de 2016}

Então era uma mesa assim, comprida no barracão, a mesa dos foliões. Ai era servido o povão que chegava.

Ao descrever a organização da festa, remete-se aos laços de sociabilidade entre os agentes, desde a doação da prenda e a seleção dos que devem se sentar no local de prestígio da festa. Sobre a organização, o entrevistado afirma que eram os próprios moradores da colônia que se incumbiam da função, uma espécie de celebração comunitária, que em si colocava em evidência a presença dos santos de devoção familiar na coletividade social. Segundo o mesmo, em sua família, seu pai em muitos momentos assumia o papel de festeiro da celebração, organizando os espaços de jornada das Folias que não só saiam em período de Reis, mas em outros períodos de celebração de outros santos, também comemorados com festas no meio social da colônia e do patrimônio.

Nas entrevistas de Francisco Garbosi percebemos no tecer da memória deste período, duas posições claras em relação à tradição de Reis na região cafeeira que envolvia os patrimônios de Irerê e Paiquerê. A primeira se estrutura na construção de um imaginário predominante na região, à figura do "pioneiro", o desbravador, aquele que abre caminho para os demais, muito comum. Enquanto que a segunda característica que parece ser o foco central e condutor de suas lembranças. Ao rememorar este período, se remete ao carisma de seu pai, a sua capacidade de mobilizar uma rede de relações para a organização de uma festa. Concentrando em sua figura a legitimidade da tradição, refletindo no campo social do qual pertence o agente, a sua posição de prestígio social e em determinadas situações econômico diante dos demais.

\section{O DESLOCAMENTO PARA O ESPAÇO URBANO: ENTRE O TRABALHO E A PRESERVAÇÃO DA TRADIÇÃO}

$\mathrm{Na}$ fala de Francisco Garbosi acerca de sua vinda para a área urbana da cidade no início da década de 1970 , tem-se nas transformações na cultura agrícola da região e a miséria no campo os elementos determinantes em sua decisão. Visto que a cidade de Londrina (PR), neste momento, encontrava-se um surto de industrialização.

Sua vinda para o município ocorreu no ano de 1972 e, com isso, também, uma ruptura aconteceu em seu cotidiano cultural. O meio rural foi a base de sua formação social e cultural, o espaço urbano obrigou-o a uma reorientação, uma adaptação ao seu novo cotidiano social. Ao relembrar a sua vinda para a Vila Siam, o entrevistado projeta em sua fala uma noção clara de recomeço:

Eu no caso, trouxe uma viola velha e umas mala... Um saco de roupa. Mobília nada.

Nada.

A figura que se constrói em sua fala remete a sentimento de fracasso, de um empobrecimento que vê no espaço urbano a chance de recomeçar. Neste mesmo ano ingressou na empresa de transporte Viação Garcia, trabalhava como cobrador. Transferindo-se em 1975 para a Viação Urbana Londrinense, empresa em que trabalhou até o ano de 1989. Neste período, suas atividades de folião de Reis ficaram suspensas, em detrimento do trabalho. 


\section{SEMINÁRIO DE PESQUISA EM CIÊNCIAS HUMANAS - SEPECH \\ Humanidades, Estado e desafios didático-científicos \\ Londrina, 27 a 29 de julho de 2016}

Não havia espaço para o dia de santo na vida urbana. Nos patrimônios em dia de seus santos de devoção, muitos colonos não trabalham, assim como não deixa de cumprir a jornada de sua bandeira.

Neste sentido, a prática e a responsabilidade do contrato firmado com os santos de devoção estavam inseridas na rotina social, contribuindo também para a definição e organização dos atos seculares destes indivíduos.

A transferência para o espaço urbano, ainda nos anos de 1970, reflete um primeiro momento de adequação do ciclo de vida do embaixador. Percebe-se em sua fala a compreensão de que o dia de Reis corresponde a um contrato entre este e os santos e a uma prática ritualística estruturada por um contrato (o dia de santo). Neste sentido, o espaço social surge como um determinante para a compreensão da lógica de sociabilidade e devocional estruturadas no rito (ZALUAR, 1980). A dicotomia entre o espaço de sociabilidade em núcleos rurais e a lógica social que envolve o espaço urbano se materializa de forma determinante na relação que Francisco Garbosi mantém com a sua profissão de fé. O período de suspensão de sua bandeira, até o retorno em 1989.

Neste mesmo ano coloca em "giro" a bandeira da Companhia de Reis Mensageiros da Paz. Os ensaios e as reuniões são realizados em sua residência. Acerca da formação e manutenção dos membros da Companhia, afirma ser algo muito dinâmico, pois muitos foliões são transitórios, sendo substituídos por outros músicos que são apresentados à Companhia por intermédio de algum folião ou ex-folião, ou convidados pelo próprio embaixador. Em 2008 quando realizei meu último levantamento no grupo, a Companhia era composta por quinze integrantes, sendo mais da metade da Companhia composta por irmãos, filhas, genro e netos do embaixador, centralizando a Companhia em seu núcleo familiar. Eram em sua maioria: aposentados, pedreiros, funcionários públicos e donas de casa, quase todos católicos (o folião Sebastião Garbossi Sobrinho, irmão do senhor Farncisco Garbosi é batista) e, na grande maioria, atuantes em suas respectivas paróquias, oriundos de áreas rurais da região vindos para o núcleo urbano de Londrina, por volta do início dos anos de 1980.

Neste período havia a presença de duas crianças e um jovem, ambos netos de Francisco Garbosi. Nenhum jovem a mais. A média etária do grupo transitava entre os 65 anos, sendo os mais jovens (exceto as crianças), as filhas de Garbosi de 36 e 35 anos.

Já neste período, Francisco Garbosi falava de forma menos incisiva sobre o desinteresse dos jovens por essa tradição. Porém, apresentava nas entrevistas a preocupação em promover a manutenção da Folia de Reis. Desde de 2002 quando do lançamento de seu livro "História, Mensagens e Embaixadas de Folia de Reis: Quem eram os magos?", como principal nome desta tradição procura registrar a tradição de Reis seja na literatura. Uma literatura quase pedagógica, visto que o teor de seus livros oficializa a sua interpretação da tradição, oficializando-a no imaginário de seus leitores e companheiros de folias. Atua na organização de eventos e na promoção da tradição na imprensa escrita e televisiva local. Tais medidas refletem uma única preocupação: a ausência de uma renovação na estrutura interna de sua Companhia.

Atualmente na região norte de Londrina (PR), apenas a sua bandeira circula parcamente entre as residências dos bairros que lhe envolvem. A idade dos foliões diminui o tempo da jornada e o espaço de cobertura da Companhia.

\footnotetext{
${ }^{7}$ Corresponde no rito à jornada, ou percurso da bandeira entre as residências que a recebem nos bairros, é expressão utilizada pelos foliões para definir o deslocamento diário ou total da bandeira ao longo do período de jornada.
} 


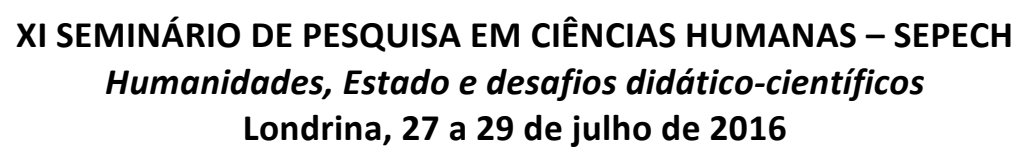

\section{DA MARGINALIDADE PARA O FIM}

Como visto ao longo do texto, a tradição de Folia de Reis está diretamente associada a um universo formador de seus foliões. De tradição doméstica, essa tradição se vê profundamente ameaçada por lacunas etárias. Atualmente, dentro do município de Londrina (PR) apenas duas bandeiras mantem o giro com regularidade. Tal situação justifica a preocupação de Francisco Garbosi ao longo das entrevistas realizadas dentro da pesquisa e em muitas de suas colocações na imprensa local.

Neste sentido, em percebe-se no conjunto de entrevistas, uma estratégia que volta-se a busca de legitimidade da tradição devocional diante do universo religioso (giros de bandeira que se encerram dentro da igreja), promovendo muitas vezes reconfigurações do rito assim como, a partir de uma participação mais incisiva dentro de suas comunidades religiosas, uma reorientação ético-religiosa dos agentes que compõem estas Companhias (esse princípio presente nas reconstruções simbólicas dos gestos e das narrativas ao longo do conjunto de entrevistas).

\section{REFERENCIAL BIBLIOGRÁFICO}

ALMEIDA, Ana Maria Chiarotti. A Morada do Vale: Sociabilidade e Representações - um estudo sobre as famílias pioneiras do Heimtal. Londrina: editora UEL, 1997.

BRANDÃO, Carlos Rodrigues. Sacerdotes de viola: Os Rituais Religiosos do Catolicismo Popular em São Paulo e em Minas Gerais. Petrópolis: Vozes, 1981.

BRANDÃO, Carlos Rodrigues. Memórias do Sagrado: estudos de religião e ritual. São Paulo: Paulinas, 1985.

ZALUAR, Alba. Milagre e castigo divino. In: Revista Religião e Sociedade. Copacabana, pp. 161-88, Tempo e Presença Editora, $n^{\circ}$. 5, junho de 1980.

ZALUAR, Alba. Os Homens de Deus: um estudo dos santos e das festas no catolicismo popular. Rio de Janeiro, Zahar Editores, 1983. 